\title{
Prospects And Problems Of Electronic Marketing Application: The Nigerian Perspective
}

\author{
Obi Keneth \\ Department of Marketing, \\ Imo State Polytechnic, Umuagwo, Nigeria
}

\begin{abstract}
This paper focused on benefits and challenges of electronic marketing application, taking insights from Nigeria. It also looked at necessary conditions that must be put in place before electronic marketing will thrive. Conclusion and recommendations were made as to how the perceived challenges facing electronic marketing adoption can be overcome.
\end{abstract}

Keywords: Electronic marketing, application, benefits and challenges.

\section{INTRODUCTION}

Electronic marketing has indeed brought about a paradigm shift in the buying and selling of goods and services in such a way that the survival of organizations whether profit or non-profit oriented will to a great extent depend on its application, from all indications.

Electronic marketing approach just like marketing has witnessed tremendous evolution in the preceding decades. E-marketing became prominent in the 19th century with the aid of telegraph and subsequently other electronic medium which include; radio, television and cable network subsequently emerged Onuoha (2010).

As opined by Kotler and Keller (2006), Anukam and Iweka (2016) which is also a common held view by marketing authors; electronic marketing, on-line marketing, digital market, are not mutually exclusive and are used interchangeably in extant marketing literature.

The problem facing marketers is the need to remain competitive, in a world of intense competition. To achieve this objective requires change in marketing orientation and strategies. The traditional marketing approach which is off-line based which is also referred to as marketing in "brick and mortar" has inherent limitations arising from its very nature as empirical studies reveal. Among the limitations of traditional marketing include but not limited to- physical contact between buyers and sellers before transaction can be concluded, limited customers and potential customers to serve, impracticable to provide bespoke goods and services to large members of customers and customer relationship maintenance challenge. With these shortcomings in sight, the application of electronic marketing becomes the only panacea to overcome these obvious limitations.

In the light of the above, thus paper attempts to introduce the term and concept of electronic marketing, highlight necessary conditions for e-marketing application, discuss the advantages of electronic marketing application, discuss some of the challenges facing electronic marketing application especially in the Nigerian context and finally make conclusion and recommendations. 


\section{ELECTRONIC MARKETING: MEANING}

The term electronic marketing has a plethora of definitions and has been viewed from various perspectives. According to Kotler and Keller (2006) e-marketing portrays company's effort to inform and communicate with buyers and promote and sell its products and services over the internet.

In his view Delone and Mc lean (2004) opines that electronic marketing deals with the facilitation of transactions and selling of product on-line either via internet or any other telecommunications network.

In the same vein, Boone and Kurtz (2004) see electronic marketing as a strategic process that creates, distributes, promotes, prices products and services to a target market over the internet or through such digital too is as fax machines, computers modems, telephone and CD ROMs.

For Jobber (2004) e-marketing is any application of a wide range of network communication technology including mobile phones, digital television in the pursuit of marketing objective.

Implicit from the definitions is that electronic marketing:-

1. Relies extensively on the internet as a major driving force.

2. Its aim is to increase the marketers reach with its concomitant benefits.

3. Is facilitated or done through the aid of an electronic medium.

\section{Necessary Conditions for E-Marketing Application}

To start up e-marketing and run it successfully, certain facilities must be provided as noted by Olayiwola et.al (2013). which is in congruence with Anukam and Iweka (2018).

* A complete configuration that is internet reading and has current facilities to operate.

* Internet network configuration that is fast and reliable for easy access to internet.

* Regular power supply to promptly attend to customers' needs and wants.

* Website package should be provided by a web designer to perform audio, graphic, video and text function.

* Establishment of a payment system that is convenient to customers

* Qualified and experienced I.T Personal to run the e-marketing facility and attend to customers.

* Security arrangement - The installation and continued update of facility that protect customers and their various transactions from fraud.

* Customer Service System- Adequate arrangement and attention should be given to customer care to ensure customer satisfaction and minimizing delays or waiting time.

\section{Benefits/Prospects of Electronic Market Application for Nigeria}

A lot of prospects or benefits are inherent with the practice of electronic marketing. Shokan (2006), Kotler and Keller (2006) enumerated some of the benefits or prospects of e-marketing to include:-

i. Disintermediation: This is the elimination of middle men with its associated cost and involves the one-on-one marketing where sellers sell to buyers directly.

ii. Speed in Transaction: transaction takes place within seconds, minutes through telephone or other telecoms through an electronic media.

iii. Immediate Feedback: Sellers get immediate feedback about their products which will enable them redesign or improve the quality of products and services to suit customers taste.

iv. Cost of Selling and Distribution is Very Low: The e-marketer need not pay for warehouse or hire sales agents or persons. This makes products sold through this 
means relatively cheap. Also in the buyers side, there is elimination of road accidents in sourcing for products and services.

v. Volume of Transaction is Very Large: E-marketing platforms connects millions of buyers world aide via the web site. ie (www). hence, millions of buyers entails greater sales and by extension profitability.

vi. Wider Scope of Market: Unlike the traditional marketing approach that markets products and services to people in a specific geographic area, the reach of e-marketing is wide as it links up buyers and sellers who are in various parts of the globe.

vii. Closer and direct relationship exist between the buyer and the seller. This guarantees customer retention as it entails exchange of information.

viii. Customization of Products and Services: Since information pertaining to customers is at the disposal of the e-marketer i.e "data bank", the seller is better equipped to provide the numerous customers with bespoke products and services which is different from the standard products available in the market.

ix. 24/7/365 Services: E-marketing avails the sellers the opportunity to sell their products and services 24 hours a day, 7 days a week and 365 days in a year without observing weekend breaks or not selling in the night time. It provides round the clock access to products and services.

\section{Challenges/Problems of Effective Application of Electronic Marketing Particularly in the Nigerian Context}

There is no doubt that Nigeria as a developing country is lagging behind the developed ones as it concerns electronic marketing application, just as it is in other spheres of life. Some of the common problems that have been adduced to be responsible for the slow pace of e-marketing application in Nigeria include the following: Wikipedia (2018) which is congruent with Onuoha (2010).

i. Scale of Operation: many companies in Nigeria are very small, as such finds it difficult to raise fund to establish and run e-marketing platforms which is obviously expensive to install and maintain.

ii. Security Concern: There is the challenge of determined mode and security of payment. Internet fraud or cyber crimes are increasing at an alarming rate, as a result eroding the confidence of potential and intending e-marketing buyers and sellers.

iii. Irregular Power Supply or total absence of power supply in some locations continues to impede e-marketing application in the Nigerian as e-marketing facilities depends on electricity to operate.

iv. Poor Service Network: No doubt, poor service network has been blamed for the low rate of electronic marketing application. Most internet service providers (ISP) experience fluctuations in their service. This affects smooth e-marketing operation

v. Low Computer Literacy Rate: Nigeria has very few people who are computer literate. Also, the general literacy rate of Nigeria is not very encouraging and supportive of emarketing comparative to developed countries of the world. literacy as used here is the ability to read and right.

vi. Inadequate I.C.T Experts: Nigeria is faced with inadequate skilled I.C.T experts to managed and maintain e-platforms. This no doubt contributes to slow usage or application of electronic marketing.

vii. High installation Cost: The cost of facilities needed to effectively run e-marketing is high. This is not unconnected with the high inflation and exchange rate prevalent in the Nigeria environment. The installation cost include the cost of computers, generators web design and payment of I.C.T experts. 


\section{CONCLUSION}

There is no doubt that the future market place will be predominantly electronic driving and online based, as significant growth in online markets and online buying and selling as evidenced by the phenomenal rise in online shops sales volume speaks volumes. The success story of Jumia and other online shops in Nigeria is worth mentioning. Certain facilities that must be put in place before electronic marketing can commence have been considered.

The numerous benefits of electronic marketing which have been x-rayed speak volume of the need for it adoption. Empirical findings suggest adopting electronic marketing will guarantee access to wider markets, ensure prompt customer feedback, provide useful data for customization and ensure customer retention among others. The practice of electronic marketing in Nigeria is faced with obvious challenges as have been discussed. In the light of the above, the researcher presents the following recommendations.

\section{RECOMMENDATIONS}

$>$ Adequate security measures should be put in place to protect online buyers and to allay their fears.

$>$ Efforts should be made by the government at all level to improve power supply.

$>$ Computer literacy should be given more attention in our schools. Practical knowledge of computer should be encouraged by setting up computer training institutes and centres at subsidized rate.

$>$ Online buyers should be giving enough incentives to discourage offline buying.

$>$ Products advertised online should be a replica of what they represent in real life. Editing of pictures to look more attractive and misleading should be avoided.

\section{References}

Aduloju Olayiwola, Peter O, Kayode A, John M, Emmanuel Busari O.A (2013). Distance learning Modules, Lagos: Ojik press.

Anukam I.A. \& Iweka (2018). E-marketing: Business Anytime, Anywhere, Joe Mankpa publishers.

Avantika monappa (2007) Definition of Digital Marketing. Retrieved 27/6/18

http://www.simplelearn.com>authors.

Boone, L.E. and Kurtz D.L. (2004) Contemporary Marketing Thompson learning, U.S.A.

Delone, W.H \& Mclean E. R (2004) measuring E-commerce success: "applying the Delone and Mclean information System success model" International Journal of electronic commerce 9(1), pp. 31 - 47.

E-marketing Mix. Retrieved 18/6/18. http://www.learnmarketing.net/emarketing.htm.

Jobber D. (2004). Principles and practice of marketing (4th edition), London, MA: Addison Wesley Longman Inc. Kotler P and Keller KL (2006). Marketing Management, Pearson Prentice Hall

Maclayton Dw \& Gladson G.N (2002) Dynamic of Product Management Avan-Panno Global Ltd, Owerri.

Nwokah N.G., Hamilton, D.I \& Ugorji, E.I.(2006). E-commerce and Internet Marketing Portharcourt, Man-Phillips Publication.

Online survey report (2017). Retrieved http://www.philipsconsulting.net/surver report.

Onuoha J.K. Ezekwe C.A. and Egbuta A.O (2010) Electronic/Internet Marketing. Cape publishers In't Ltd.

Shoken O.O. (2006). Electronic Marketing Lagos; Shona investment company Ltd.

Ugorji G.C (2008). Internet Marketing and E-commerce Strategies: Benin: Higher ground Business Association. 